\title{
Ubiquitous Computing in Precision Agriculture: A Systematic Review
}

Gilson Augusto Helfer ${ }^{1}$, Jorge Luís Victoria Barbosa ${ }^{1}$, Bruno Guilherme Martini ${ }^{1}$, Ronaldo Bastos dos Santos ${ }^{2}$, Adilson Ben da Costa ${ }^{2}$

\author{
${ }^{1}$ Applied Computing Graduate Program, University of Vale do Rio dos Sinos, São Leopoldo, Brazil \\ ${ }^{2}$ Industrial Systems and Processes Graduate Program, University of Santa Cruz do Sul, Brazil
}

\begin{abstract}
The applications of ubiquitous computing have increased in recent years, especially due to the development of technologies such as mobile computing and its integration with the real world. One of the challenges in this area is the use of context sensitivity. In agriculture, this can be considered as the context related to the environment, such as the chemical and physical aspects that characterize the different soil types. This scenario periodically changes due to factors such as climate, type of cultivar and soil management technique used, among other aspects. This article presents a systematic review on the research works that explore ubiquitous computing in precision agriculture, including which technologies are being currently applied and which gap scan still be researched. Nine scientific repositories were explored to find articles about precision agriculture and ubiquitous computing. As a result of this search and filtering process, 32 works were reviewed, analyzed and categorized between the years of 2009 and 2019. In general, the reviewed articles concentrate on problems arising from the communication between sensors and the management of context-sensitive data.
\end{abstract}

\section{Keywords}

Systematic review, ubiquitous, computing, precision agriculture.

Helfer, G. A., Barbosa, J. L. V., Martini, B. G., dos Santos, R. B. and da Costa A. B.(2019) "Ubiquitous Computing in Precision Agriculture: A Systematic Review", AGRIS on-line Papers in Economics and Informatics, Vol. 11, No. 4, pp. 3-13. ISSN 1804-1930. DOI 10.7160/aol.2019.110401.

\section{Introduction}

Precision agriculture is a suitable strategy to increase productivity, which al-lows the rational use of inputs and reduces the environmental impacts caused by agricultural practices. Currently, the inputs are used in a variable way to meet the specific needs of each location, thus optimizing the production process. However, it is necessary to characterize the soil spatial variability to check chemical and physical attributes through several representative sampling (Costa, de Passos et al., 2014; Bonfante et al., 2017).

Generally, computing research has aimed to develop techniques to integrate information technology into people's daily lives, so that they are proactively assisted by technology while they execute their daily activities (Weiser, 1999). Ubiquitous computing seeks new forms of communication and interaction that are distributed in the environment, either in a perceptible or imperceptible way. Furthermore, through the use of sensors, computers can detect and extract data from the environment, which helps users to perform their tasks (Satyanarayanan, 2001).

Context-aware applications are necessary for this vision to become real-ity (Dey et al., 2001). Context means any information that allows the characterization of an entity situation that is relevant to the interaction between a user and an application, which includes information about the situation, identity and lo-cation of people, groups and physical or computational objects. Through the knowledge of contextual data, an application can adjust its own functioning or even act proactively, such as by alerting users ' to a specific scenario or aiding them to develop activities more efficiently. The generated information will enable the construction of a historical database for posterior decision making (Hong et al., 2009; Ciaramella et al., 2010).

This article uses the systematic review methodology developed by Petersen et al. (2008) to conduct a review of the use of ubiquitous computing 
in agriculture. Guided by the search and two-phase processing, this article concentrates on discovering the main authors in this area. This article also looks for the most relevant works, in addition to the possible research gaps and their challenges.

\section{Materials and methods}

This article uses a systematic review methodology to" identify, analyze and interpret all the available evidence related to a specific research question" (Kitchenham \& Charters, 2007), which in this case are relevant to the application of ubiquitous computing imprecision agriculture. This type of methodology not only discusses the conclusion but also examines all of the activities related to the discovery. Hence, a systematic study collects data when the activity occurs and the media in which it was published, and then maps this connection (Cooper, 2016). The methodology consists in the execution of the following steps: a) establish research questions; b) design the process of the research and c) define criteria for filtering results.

\section{Research questions}

The research questions led this study to discover works related to the theme. The goal of these questions is to understand how ubiquitous technologies are being used to help in precision agriculture. It is also desirable to find how specific technologies are applied between agriculture and context awareness. Finally, clusters of commonly used terms within selected articles were generated to support the identification of academic research interest trends. Therefore, five questions were established and presented in Table 1.

\begin{tabular}{|l|l|}
\hline References & Questions \\
\hline RQ1 & $\begin{array}{l}\text { Which technologies support precision } \\
\text { agriculture? }\end{array}$ \\
\hline RQ2 & $\begin{array}{l}\text { Where are these technologies being applied } \\
\text { in precision agriculture? }\end{array}$ \\
\hline RQ3 & $\begin{array}{l}\text { How is ubiquitous computing being used } \\
\text { to support precision agriculture? }\end{array}$ \\
\hline RQ4 & $\begin{array}{l}\text { Which are the main clusters of research that } \\
\text { express the terms ubiquitous computing } \\
\text { and precision agriculture? }\end{array}$ \\
\hline RQ5 & $\begin{array}{l}\text { What is the number of publications per database } \\
\text { and per year? }\end{array}$ \\
\hline
\end{tabular}

Source: own processing

Table 1: Research questions.

\section{Research process}

Petersen et al. (2008) defined three stages of a research process: specify the search string, choose the databases to apply them and then get the results. The first stage starts by identifying the keywords and their related terms. In this study, we chose the keywords "Ubiquitous" and "Agriculture" and also other related terms, as indicated in Table 2.

\begin{tabular}{|l|l|}
\hline Keyword & Related terms \\
\hline Ubiquitous & $\begin{array}{l}\text { Context-aware OR Context-sensitive OR } \\
\text { Context awareness OR Pervasive OR } \\
\text { Internet-of-things OR IoT }\end{array}$ \\
\hline Agriculture & Agronomy OR Soil \\
\hline
\end{tabular}

Source: own processing

Table 2: Search terms.

These terms generated the following search string to be used in the search databases:((ubiquitous OR context-aware OR context-sensitive OR context awareness OR pervasive OR internet-of-things OR iot) AND (agriculture OR agronomy OR soil)). The term "soil" was inserted in the search string because the term "agriculture" covers other sub-areas of application, such as aquaponic, permaculture, indoors agriculture, organic, subsistence, among others. This enabled this study to filter only the works related to intensive agriculture applied to the soil; that is, that have high productivity, large extensions of land and the use of modern techniques and mechanizations.

Once the search string was defined, we constructed the research parameters to be used on the databases. In the second step, we selected eight re-search databases relevant to the area of computing, including the ACM Digital Library, Semantic Scholar (Citeseerx), Google Scholar, IEEE Xplore Digital Library, Scopus, Science Direct, Springer and Wiley Library. Research in the ACM Digital Library required the use of advanced search features, where each of our strings was inserted in the "Edit Query" tool. Similarly, this practice was applied in the Semantic Scholar (CiteSeerX), Google Scholar, IEEE Xplore and Scopus databases. Only in the Science Direct and Google Scholar base was the string applied in a simple search box that is available on the main page of these sites.

\section{Filters application}

To filter the most relevant works, we generated the following Inclusion Criteria (IC) for this selection: 
-IC1: The study must be published in a conference proceeding or journal.

-IC2: The study must be related to the context of use of ubiquitous com-putting in agriculture.

-IC3: The study must be a full paper.

In turn, the Excluding Criteria (EC) were also defined, as follows:

-EC1: Studies published before 2009.

-EC2: Studies that are not written in English.

-EC3: Studies related to theses or dissertations.

-EC4: Studies that are not related to research questions.

The inclusion and exclusion criteria helped the filtering process to obtain the most relevant studies and to eliminate any noise generated during the search. The studies obtained in the search process were filtered, and those that did not fit in the inclusion criteria were removed. The articles were stored in the Mendeley Desktop $C$ program and organized in specific folders to each database. The next step was to analyze the works by title and abstract, so that they could be later combined in the same folder. Six articles were added by heuristic because they are relevant for this study, even though they were not found during the search process.
The next filter was based on the first two passes of the three-pass approach introduced by Srinivasan Keshav (Keshav, 2007). The first pass is a quick sweep, consisting of: 1) reading the title, the abstract and the introduction; 2) reading only the heading of the section and subsection, but ignoring all the rest; 3) looking the mathematical contents (if there is any) to determine the underlaying theoretical fundamentals; and 4) reading the conclusions. The second pass consisted of carefully analyzing the figures, diagrams and any other illustrations in the article, giving special attention to the graphics. Finally, the remaining articles were filtered by the analysis of the full text and the observation of the exclusion criteria EC4.

Figure 1 presents the filtering process, with IC and EC applied at each stage, with the Scopus and Science Direct databases bringing together more assertive works related to the search string with $46.4 \%$ of the filtered results. The Semantic Scholar and Wiley databases presented many unrelated works.

Figure 2 shows the result of this processing before the article combination stage. The filtering process also brought works related to subareas of computation, such as hardware architecture and networks applied to precision agriculture.

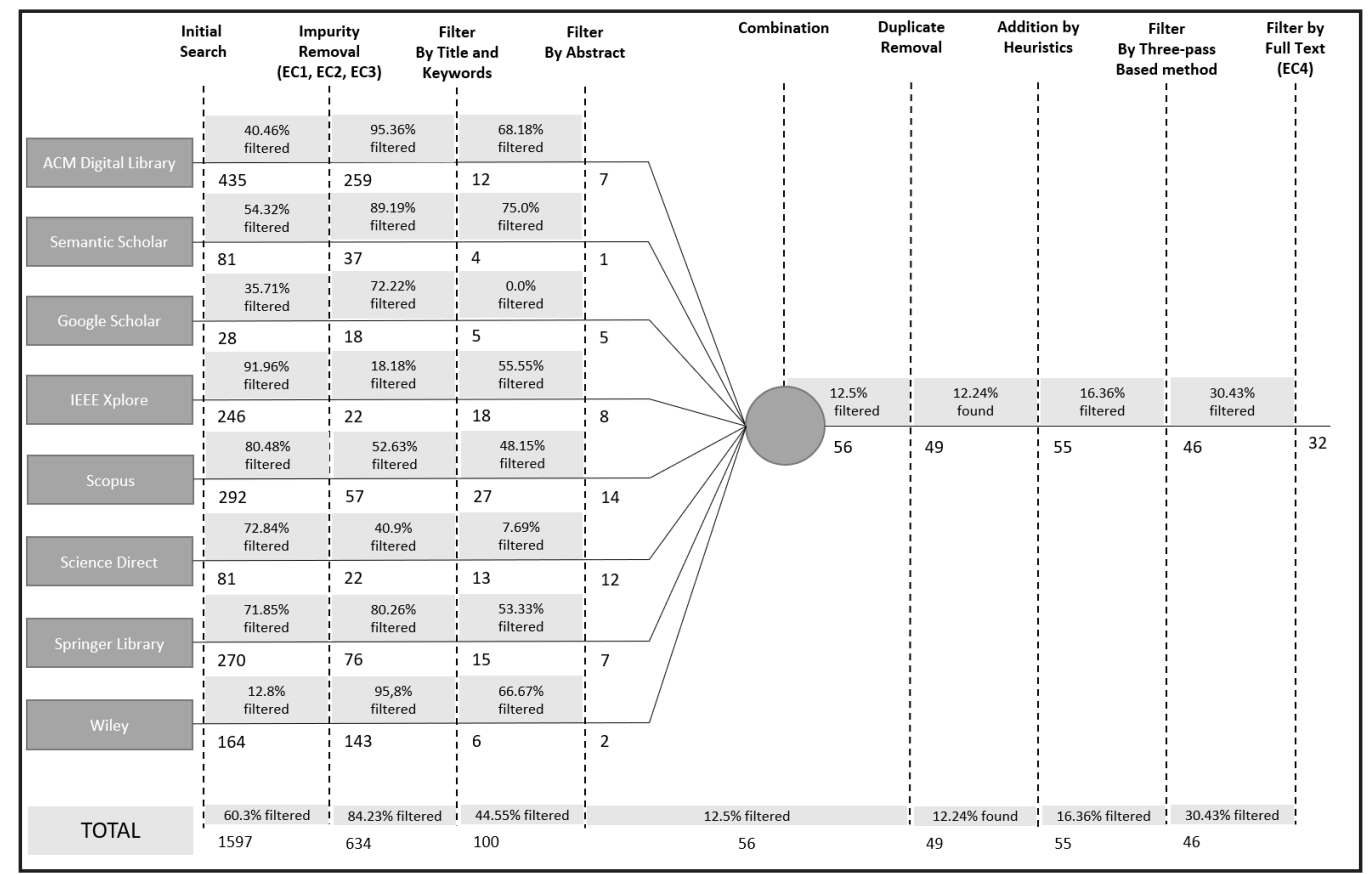

Source: Own processing

Figure 1: Stages of the filtering process. 


\section{Threats to validity}

As in any work involving a systematic review, this research presents some risks that can affect the obtained results. These risks are directly related to the data filtering process. To reduce the risk margin, this research searched data in nine different databases, selected from their relevance in the areas of ubiquitous computing and agriculture.

The research string was constructed considering the main terms and some related words to ensure the greatest possible coverage of keywords in the search, avoiding an ineffective search.

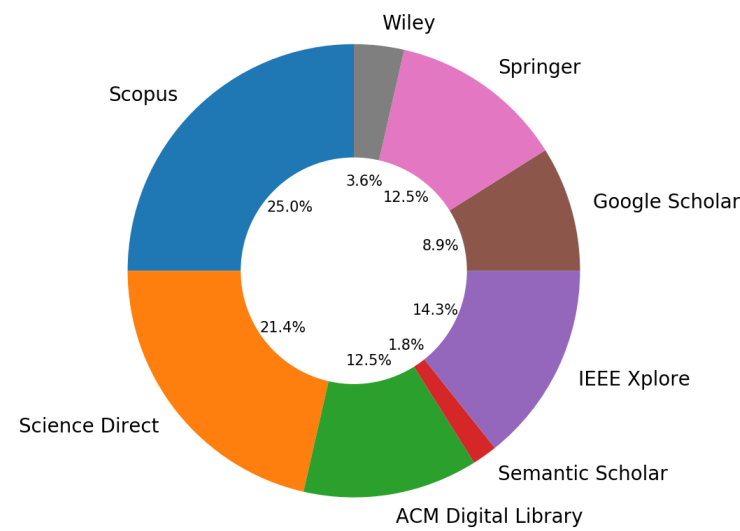

Source: Own processing

Figure 2: Databases where the researches were found before the combination stage.

The Petersen technique was used to mitigate the risk that important works may have been removed from the research (Petersen et al., 2008). During this process, articles were analyzed and selected without a reviewer. To reduce the risks that the results may have been affected, we used the review process already handled by other authors (Díaz et al., 2011; Vianna \& Barbosa, 2017), we also used software that supports this selection process, especially the Mendeley Desktop@ program.

\section{Results and discussion}

This section details the survey results obtained by reading and analyzing the 32 mapped studies. In addition, the research questions were answered and additional discussions and analysis on the studies were presented.

\section{RQ1 - Which technologies support precision} agriculture?

The technologies that support precision agriculture were analyzed and categorized as IoT \& Sensors Applications, Architecture Model, Semantic
\& Ontology and, finally, Wireless Network Sensor (WSN). Table 3 maps the works with their categorization.

Based on this question, most of articles focused on WSN. There is a big difference between IoT and WSN, which causes these terms to have been categorized separately. In an IoT system, all of the sensors directly send their information to the Internet, such as soil temperature and moisture. In this case, a direct connection to the Internet will be open immediately or periodically to synchronize data. Already in a WSN, the various sensors connect to some kind of router or central node. A large collection of sensors, as in a mesh network, can be used to individually gather data and send data through a router to the Internet in an IoT system. In other words, WSN is a subset of IoT.

\begin{tabular}{|c|c|c|}
\hline Technology & Articles & Percentual \\
\hline $\begin{array}{l}\text { IoT } \\
\text { and Sensors }\end{array}$ & $\begin{array}{l}\text { (Nash, Korduan et al., 2009), } \\
\text { (Córdoba, Bruno et al., 2013), } \\
\text { (Stojanovic, Falconer et al., } \\
\text { 2017), (Phillips, Newlands } \\
\text { et al., 2014), (Georgakopoulos } \\
\text { and Jayaraman, 2016), } \\
\text { (Tzounis, Katsoulas et al., } \\
\text { 2017), (Shao, Meng } \\
\text { et al., 2017), (Aswathy } \\
\text { and Malarvizhi, 2018), } \\
\text { (Dobrescu, Merezeanu et al., } \\
\text { 2019), (AlZu'bi, Hawashin } \\
\text { et al., 2019) }\end{array}$ & $31.25 \%$ \\
\hline $\begin{array}{l}\text { Architecture } \\
\text { Model }\end{array}$ & $\begin{array}{l}\text { (Steinberger, Rothmund } \\
\text { et al., 2009), (Cho, Moon et al., } \\
\text { 2011), (Kaloxylos, Groumas } \\
\text { et al., 2014), (Lopes, Souza } \\
\text { et al., 2014), (Gelogo, Un-Bae } \\
\text { et al., 2014), (Babou, Sane } \\
\text { et al., 2019), (Jearanaiwongkul, } \\
\text { Andres et al., 2019), (Cho, } \\
\text { 2019) }\end{array}$ & $25.00 \%$ \\
\hline $\begin{array}{l}\text { Semantic } \\
\text { and Ontology }\end{array}$ & $\begin{array}{l}\text { (Sivamani, Bae et al., 2013), } \\
\text { (Schuster, Lee et al., 2011) }\end{array}$ & $6.25 \%$ \\
\hline WSN & $\begin{array}{l}\text { (Lee, Hwang et al., 2010), } \\
\text { (Díaz, Pérez et al., 2011), } \\
\text { (Sabri, Aljunid et al., 2012), } \\
\text { (Kaloxylos, Eigenmann et al., } \\
\text { 2012), (Rawat, Singh et al., } \\
\text { 2014), (Shi, Li et al., 2014), } \\
\text { (Ndzi, Harun et al., 2014), } \\
\text { (Bhanu, Reddy et al., 2019), } \\
\text { (Simbeye, 2020), (Ali, Ming } \\
\text { et al., 2017), (Sivamani, } \\
\text { Choi et al., 2018), (Keswani, } \\
\text { Mohapatra et al., 2019) }\end{array}$ & $37.50 \%$ \\
\hline
\end{tabular}

Source: Own processing

Table 3: Technologies that support precision agriculture. 
RQ2 - Where are these technologies being applied in precision agriculture?

Analyzing the results according to Table 4, most technology applied in precision agriculture was about improvements of communication between sensors, in the same direction that RQ1 appointed. network communication followed by the soil analysis and context sensitive applications. In this last case, the control centers collect and process data in real time to help the farmers to make the best decisions related to planting, fertilizing and harvesting.

\begin{tabular}{|c|c|c|}
\hline Technology & Articles & Percentual \\
\hline $\begin{array}{l}\text { Improving } \\
\text { communication }\end{array}$ & $\begin{array}{l}\text { (Nash, Korduan et al., } \\
\text { 2009), (Stojanovic, } \\
\text { Falconer et al., 2017), } \\
\text { (Shao, Meng et al., 2017), } \\
\text { (Aswathy and Malarvizhi, } \\
\text { 2018), (Georgakopoulos } \\
\text { \& Jayaraman, 2016), } \\
\text { (Steinberger, Rothmund } \\
\text { et al., 2009), (Babou, Sane } \\
\text { et al., 2019), (Schuster, Lee } \\
\text { et al., 2011), (Lee, Hwang } \\
\text { et al., 2010), (Díaz, Pérez } \\
\text { et al., 2011), (Sabri, Aljunid } \\
\text { et al., 2012), (Kaloxylos, } \\
\text { Eigenmann et al., 2012), } \\
\text { (Rawat, Singh et al., 2014), } \\
\text { (Shi, Li et al., 2014), (Ndzi, } \\
\text { Harun et al., 2014), (Bhanu, } \\
\text { Reddy et al., 2019), (Simbeye, } \\
\text { 2020), (Ali, Ming et al., 2017) }\end{array}$ & $56.25 \%$ \\
\hline $\begin{array}{l}\text { Context } \\
\text { awareness }\end{array}$ & $\begin{array}{l}\text { (Córdoba, Bruno et al., 2013), } \\
\text { (Phillips, Newlands et al., } \\
\text { 2014), (Tzounis, Katsoulas } \\
\text { et al., 2017), (AlZu'bi, } \\
\text { Hawashin et al., 2019), } \\
\text { (Dobrescu, Merezeanu et al., } \\
\text { 2019), (Cho, Moon et al., } \\
\text { 2011), (Kaloxylos, Groumas } \\
\text { et al., 2014), (Lopes, Souza } \\
\text { et al., 2014), (Gelogo, Un-Bae } \\
\text { et al., 2014), (Jearanaiwongkul, } \\
\text { Andres et al., 2019), } \\
\text { (Sivamani, Bae et al., 2013), } \\
\text { (Cho, 2019), (Sivamani, } \\
\text { Choi et al., 2018), (Keswani, } \\
\text { Mohapatra et al., 2019) }\end{array}$ & $43.75 \%$ \\
\hline
\end{tabular}

Source: Own processing

Table 4: Applying technology in precision agriculture.

RQ3 - How is ubiquitous computing being used to support precision agriculture?

According with Table 4, there is currently a big gap (56.25\% of the articles) in improving communication between the distribution of the sensors and the base. Technology such as WSN has boosted agricultural research because there is no longer a need for cables to receive the information but instead solutions are available to avoid the loss of data, to enable synchronization and to improve sensor power efficiency.

A total of 14 articles were identified that used the contexts as defined by Dey et al. (2001). The main goal of these researchers was to improve the use of technology in favor of increased production in the planted area. The major challenge of ubiquitous computing is related to the need of the applications be context-sensitive so that, when appropriate, they respond through decision making. All of these studies of context awareness that were selected in the mapping are presented in Table 5.

RQ4 - Which are the main clusters of research that express the terms ubiquitous computing and precision agriculture?

Figure 3 presents the result of a bibliometric mapping tool known as VOSViewer, which was used to identify relevant works by publication year (Van Eck \& Waltman, 2009). It is also possible to verify the common terms within publications and interest relating to ubiquitous computing and precision agriculture. All of the selected studies focus on four terms, in order of relevance: sensor network, context, sensor node and soil. The WSN is one of the most promising technologies for the agricultural sector. WSN enables advancements in ubiquitous computing due to their availability, small size and low price, resulting in an easy and cost-effective implementation.

\section{RQ5 - What is the number of publications} per database and year?

Figure 4 presents the publications grouped according to the year of publication. However, it should be noted that the year of creation of this article (2019) is still on going and other articles could compose this statistic. In the last six years, the number of publications on agriculture and ubiquitous computing increased when compared with the rest of the beginning period, except 2015. This growth shows the interest of researchers in improving agriculture, as well as in improving the quality of products through the better monitoring of production. The number on the top of peaks indicates the total of publications, excluding duplicates.

\section{Discussion}

Only 10 studies or $31.25 \%$ of the articles used IoT and Sensors to support precision agriculture (Table 3). Among these, the most popular technology was WSN with 12 articles. 


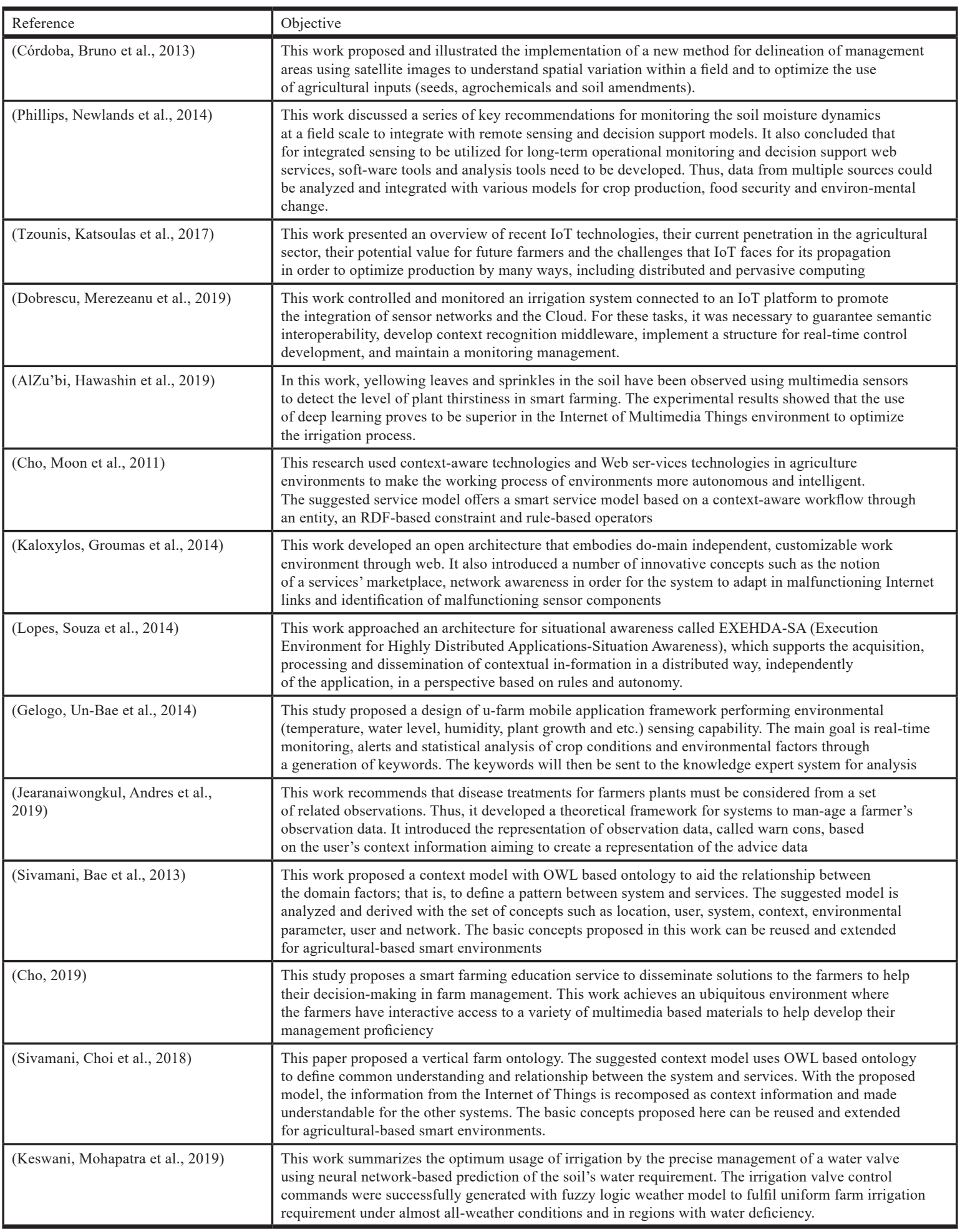

Source: Own processing

Table 5: Filtered works relation.

Table 4 shows that improving communication with WSN was the most relevant theme in the last 10 years. In terms of context awareness, the use of sensors to detect soil moisture for automated irrigation was found in five articles (Gelogo et al.,
2014; Stojanovic et al., 2017; AlZu'bi et al., 2019; Dobrescu et al., 2019; Keswani et al., 2019). However, the use of images in agriculture was found in only one article (Córdoba et al., 2013). This technique is increasing recently through the use 


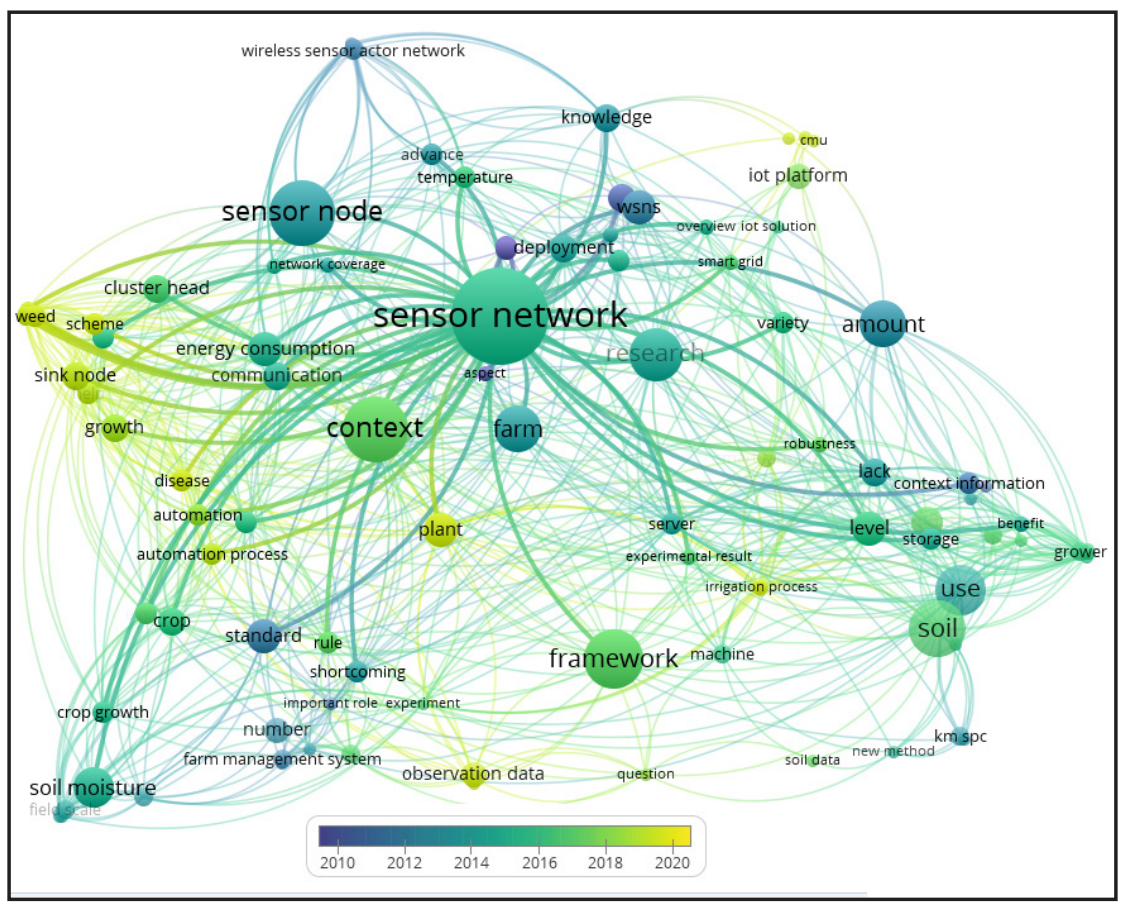

Source: Own processing

Figure 3: Density of research clusters by publication year.

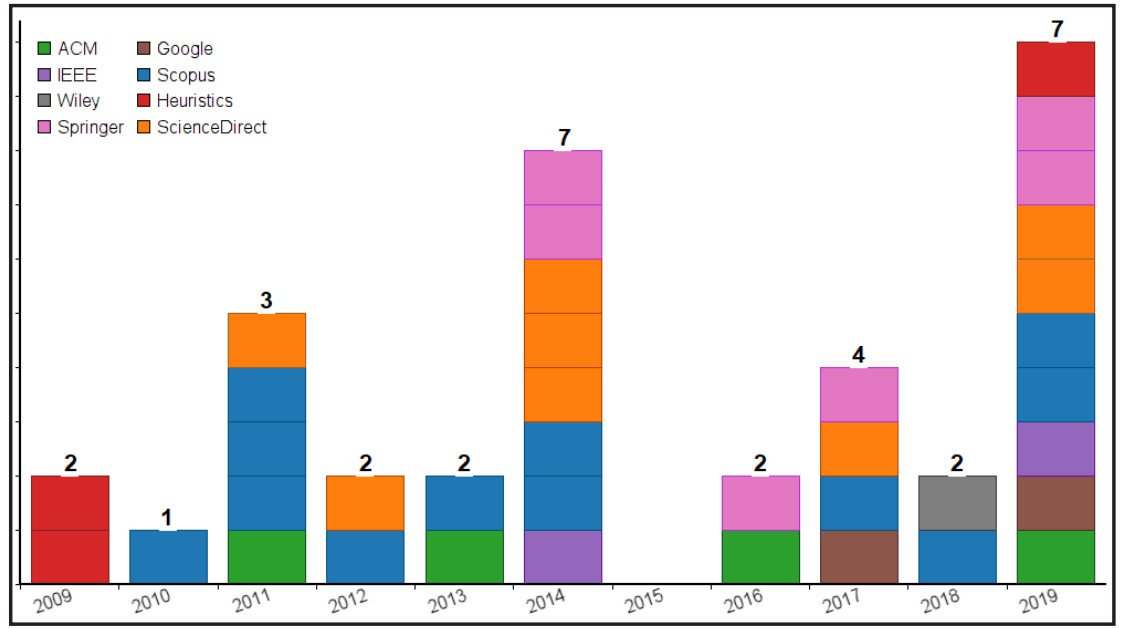

Source: Own processing

Figure 4: Number of publications between 2009 and 2019.

of drones and also because the diversity of information that can be obtained with this equipment, such as detecting plant species, plant size, fruit color and plant diseases (Parisi et al., 2019).

By analyzing the entire filtering process presented in Figure 1 and the Research Question 1 (RQ 1), which presents in which databases the articles were published, it is possible to verify that the most accurate databases that processed the query string were Google Scholar and Science Direct because they had a small number of articles in the initial survey but have a relatively high number when compared to the total articles used in the mapping. The least accurate database was Semantic Scholar of the 81 papers in the initial search, only one study was used after the last filtering.

\section{Conclusion}

This systematic review has presented the state-of-the-art in the application of ubiquitous computing in precision agriculture. Furthermore, it also presented different applications 
of technologies associated with computing for better results in agricultural production.

Although many of the selected papers aim to solve WSN problem, one of the gaps that was found during the evaluation of this research corresponds to the application of historical data in precision agriculture. In particular, none of the articles mentioned the use of a historical database and how this collected data could effectively improve production with the support of mobile technology.

Contextual data could lead to a three-dimensional spatial variability of soil conditions, such as fertility, moisture, $\mathrm{pH}$, macro and micronutrients, and other soil attributes. This type of visualization was approached by Stojanovic using yield data (Stojanovic et al., 2017).

The history of contextual data could support decision-making on the farm. In this sense, the formalization of a context (Dey et al., 2001) applied to precision agriculture would allow the generation of context histories (Rosa et al.,

Corresponding authors

Gilson Augusto Helfer

Applied Computing Graduate Program, University of Vale do Rio dos Sinos, UNISINOS

São Leopoldo, Brazil

E-mail: ghelfer@gmail.com

\section{References}

[1] Ali, A., Ming, Y., Chakraborty, S. and Iram, S. (2017) "A comprehensive survey on real-time applications of WSN", Future Internet, Vol. 9, No 4, pp. 77. ISSN 1999-5903. DOI 10.3390/fi9040077.

[2] AlZu'bi, S., Hawashin, B., Mujahed, M., Jararweh, Y. and Gupta, B. B. (2019) "An efficient employment of internet of multimedia things in smart and future agriculture", Multimedia Tools and Applications, pp. 1-25. ISSN 1380-7501. DOI 10.1007/s11042-019-7367-0.

[3] Aswathy, R. H. \& Malarvizhi, N. (2018) „Internet of things (IoT): a survey on protocols and security risks", International Journal of Engineering and Technology, Vol. 7 No. 1.7, pp. 6. ISSN 2227-524X. DOI 10.14419/ijet.v7i1.7.9380.

[4] Babou, C. S. M., Sane, B. O., Diane, I. and Niang, I. (2019) "Home Edge Computing Architecture for Smart and Sustainable Agriculture and Breeding", Proceedings of the $2^{\text {nd }}$ International Conference on Networking, Information Systems \& Security, pp. 45. ACM. ISBN 978-1-4503-6645-8. DOI 10.1145/3320326.3320377.

[5] Bhanu, K., Reddy, T. B. and Hanumanthappa, M. (2019) "Multi-agent based context aware information gathering for agriculture using Wireless Multimedia Sensor Networks", Egyptian Informatics Journal, Vol. 20, No. 1, pp.33-44. ISSN 1110-8665. DOI 10.1016/j.eij.2018.07.001.

[6] Bonfante, A., Sellami, M., Saab, M. A., Albrizio, R., Basile, A., Fahed, S., Giorio, P., Langella, G., Monaco, E. and Bouma, J. (2017) "The role of soils in the analysis of potential agricultural production: A case study in Lebanon", Agricultural systems, Vol. 156, pp. 67-75. ISSN 0308-521X. DOI 10.1016/j.agsy.2017.05.018.

2015) related to a whole plantation or areas of it. pre-dictions (da Rosa et al., 2016) of soil conditions. Therefore, the right moment for agricultural inputs distribution, such as pesticides and fertilizers, could be determined, in addition to uniformity

\section{Acknowledgements}

This study was financed in part by the Coordenação - Brasil (CAPES) - Finance Code 001, Fundação do Sul - Fapergs/Brasil (http://www.fapergs.rs.gov. br), and Conselho Nacional de Desenvolvimento Científico e Tecnológico - CNPq/Brasil the University of Vale do Rio dos Sinos - Unisinos Cruz do Sul - Unisc (http://www.unisc.br) for embracing this research. in productivity. (1) 
[7] Cho, S. Chung H., Dongil K. and Soonghee L. (2019). „Smart Farming Education Service based on u-learning environment", Proceedings of the 21st International Conference on Advanced Communication Technology, pp. 471-474. IEEE. ISBN 979-11-88428-02-1. DOI 10.23919/ICACT.2019.8701949.

[8] Cho, Y., Moon, J., Kim, I., Choi, J. and Yoe, H. (2011) „Towards a smart service based on a contextaware workflow model in u-agriculture", International Journal of Web and Grid Services, Vol. 7, No. 2, pp. 117-133. ISSN 1741-1106. DOI 10.1504/IJWGS.2011.040444.

[9] Ciaramella, A., Cimino, M. G., Lazzerini, B. and Marcelloni, F. (2010) "Using context history to personalize a resource recommender via a genetic algorithm", Proceedings of the $10^{\text {th }}$ International Conference on Intelligent Systems Design and Applications, IEEE, pp. 965-970. ISBN 978-1-4244-8134-7. DOI 10.1109/ISDA.2010.5687064.

[10] Cooper, I. D. (2016) "What is a mapping study?“, Journal of the Medical Library Association, Vol. 104, No. 1, pp. 76. ISSN 1536-5050. DOI 10.3163/1536-5050.104.1.013.

[11] Córdoba, M., Bruno, C., Costa, J. and Balzarini, M. (2013) "Subfield management class delineation using cluster analysis from spatial principal components of soil variables", Computers and Electronics in Agriculture, Vol. 97, pp. 6-14. ISSN 0168-1699. DOI 10.1016/j.compag.2013.05.009.

[12] Costa, N. R., de Passos, M., Dal Bem, E. A., Dalchiavon, F. C. and Caldas, R. R. (2014) "Produtividade de laranja correlacionada com atributos químicos do solo visando a zonas específicas de manejo“, Pesquisa Agropecuária Tropical, Vol. 44, No. 4, pp. 391-398. ISSN 1983-4063. DOI 10.1590/S1983-40632014000400001.

[13] da Rosa, J. H., Barbosa, J. L. and Ribeiro, G. D. (2016) "ORACON: An adaptive model for context prediction", Expert Systems with Applications, Vol. 45, pp. 56-70. ISSN 0957-4174. DOI 10.1016/j.eswa.2015.09.016.

[14] Dey, A. K., Abowd, G. D. and Salber, D. (2001) "A conceptual framework and a toolkit for supporting the rapid prototyping of context-aware applications", Human-Computer Interaction, Vol. 16, No. 2-4, pp. 97-166. ISSN 0737-0024. DOI 10.1207/S15327051HCI16234_02.

[15] Díaz, S. E., Pérez, J. C., Mateos, A. C., Marinescu, M.-C. and Guerra, B. B. (2011) "A novel methodology for the monitoring of the agricultural production process based on wireless sensor networks", Computers and electronics in agriculture, Vol. 76, No. 2, pp. 252-265. ISSN 0168-1699. DOI 10.1016/j.compag.2011.02.004.

[16] Dobrescu, R., Merezeanu, D. and Mocanu, S. (2019) "Context-aware control and monitoring system with IoT and cloud support", Computers and Electronics in Agriculture, Vol. 160, pp. 91-99. ISSN 0168-1699. DOI 10.1016/j.compag.2019.03.005.

[17] Gelogo, Y. E., Un-Bae, J., Woo-Jo, J. and Kim, H.-K. (2014) "Development of u-farm Mobile Application Architecture", Conference: Advanced Software Engineering \& Its Applications, Vol. 74, pp. 132-137.

[18] Georgakopoulos, D. and Jayaraman, P.P. (2016) "Internet of things: from internet scale sensing to smart services", Computing, Vol. 98, No. 10, pp. 1041-1058. ISSN 0010-485X. DOI 10.1007/s00607-016-0510-0.

[19] Hong, J., Suh, E.-H., Kim, J. and Kim, S. (2009) "Context-aware system for proactive personalized service based on context history", Expert Systems with Applications, Vol. 36 No. 4, pp. 7448-7457. ISSN 0957-4174. DOI 10.1016/j.eswa.2008.09.002.

[20] Jearanaiwongkul, W., Andres, F. and Anutariya, C. (2019) "A Formal Model for Managing Multiple Observation Data in Agriculture", International Journal of Intelligent Information Technologies (IJIIT), Vol. 15, No. 3, pp. 79-100. ISSN 1548-3657. DOI 10.4018/IJIIT.2019070105.

[21] Kaloxylos, A., Eigenmann, R., Teye, F., Politopoulou, Z., Wolfert, S., Shrank, C., Dillinger, M., Lampropoulou, I., Antoniou, E. and Pesonen, L. (2012) "Farm management systems and the Future Internet era", Computers and Electronics in Agriculture, Vol. 89, pp. 130-144. ISSN 0168-1699. DOI 10.1016/j.compag.2012.09.002. 
[22] Kaloxylos, A., Groumas, A., Sarris, V., Katsikas, L., Magdalinos, P., Antoniou, E., Politopoulou, Z., Wolfert, S., Brewster, C. and Eigenmann, R. (2014) "A cloud-based Farm Management System: Architecture and implementation", Computers and Electronics in Agriculture, Vol. 100, pp. 168-179. ISSN 0168-1699. DOI 10.1016/j.compag.2013.11.014.

[23] Keshav, S. (2007) "How to read a paper", ACM SIGCOMM Computer Communication Review, Vol. 37, No. 3, pp. 83-84. ISSN 0146-4833. DOI 10.1145/1273445.1273458.

[24] Keswani, B., Mohapatra, A. G., Mohanty, A., Khanna, A., Rodrigues, J. J., Gupta, D. and de Albuquerque, V. H. C. (2019) "Adapting weather conditions based IoT enabled smart irrigation technique in precision agriculture mechanisms", Neural Computing and Applications, Vol. 31, No. 1, pp. 277-292. ISSN 0941-0643. DOI 10.1007/s00521-018-3737-1.

[25] Kitchenham, B. and Charters, S. (2007) "Guidelines for performing systematic literature reviews in software engineering", Software Engineering Group - Keele University, Department of Computer Science - University of Durham, UK, Jul. 2007. [Online]. Available: http://citeseerx.ist.psu.edu/ viewdoc/citations?doi=10.1.1.117.471 [Accessed: 25 May, 2019].

[26] Lee, H.-C., Hwang, J.-H. and Yoe, H. (2010) "Energy efficient MAC protocol for ubiquitous agriculture", International Journal of Smart Home, Vol. 4, No. 3, pp. 15-26. ISSN 19754094. DOI 10.1007/978-3-642-17569-5_63.

[27] Lopes, J., Souza, R., Gadotti, G., Pernas, A., Yamin, A. and Geyer, C. (2014) "An architectural model for situation awareness in ubiquitous computing", IEEE Latin America Transactions, Vol. 12 No. 6, pp. 1113-1119. ISSN 1548-0992. DOI 10.1109/TLA.2014.6894008.

[28] Nash, E., Korduan, P. and Bill, R. (2009) "Applications of open geospatial web services in precision agriculture: a review", Precision Agriculture, Vol. 10, No. 6, pp. 546. ISSN 1573-1618. DOI 10.1007/s11119-009-9134-0.

[29] Ndzi, D. L., Harun, A., Ramli, F. M., Kamarudin, M. L., Zakaria, A., Shakaff, A. Y. M., Jaafar, M. N., Zhou, S. and Farook, R. S. (2014) "Wireless sensor network coverage measurement and planning in mixed crop farming", Computers and Electronics in Agriculture, Vol. 105, pp. 83-94. ISSN 0168-1699. DOI 10.1016/j.compag.2014.04.012.

[30] Parisi, E., Suma, M., Korumaz, A.G., Rosina, E. and Tucci, G. (2019) "Aerial Platforms (uav) "Surveys in the vis and TIR Range. Applications on Archaeology and Agriculture", International Archives of the Photogrammetry, Remote Sensing and Spatial Information Sciences, Vol. 42(2/W11). ISSN 2194-9034. DOI 10.5194/isprs-archives-XLII-2-W11-945-2019.

[31] Petersen, K., Feldt, R., Mujtaba, S. and Mattsson, M. (2008) "Systematic mapping studies in software engineering", Proceedings of the $12^{\text {th }}$ International Conference on Evaluation and Assessment in Software Engineering, pp. 68-77. [Online]. Available: http://dl.acm.org/citation. $\mathrm{cfm} ? \mathrm{id}=2227115.2227123$ [Accessed: 25 May. 2019].

[32] Phillips, A. J., Newlands, N. K., Liang, S. H. and Ellert, B. H. (2014) "Integrated sensing of soil moisture at the field-scale: Measuring, modeling and sharing for improved agricultural decision support", Computers and Electronics in Agriculture, Vol. 107, pp. 73-88. ISSN 0168-1699. DOI 10.1016/j.compag.2014.02.011.

[33] Rawat, P., Singh, K. D., Chaouchi, H. and Bonnin, J. M. (2014) "Wireless sensor networks: a survey on recent developments and potential synergies", The Journal of Supercomputing, Vol. 68, No. 1, pp. 1-48. ISSN 0920-8542. DOI 10.1007/s11227-013-1021-9.

[34] Rosa, J. H., Barbosa, J. L., Kich, M. and Brito, L. (2015) "A multi-temporal context-aware system for competences management", International Journal of Artificial Intelligence in Education, Vol. 25 No. 4, pp. 455-492. ISSN 1560-4292. DOI 10.1007/s40593-015-0047-y.

[35] Sabri, N., Aljunid, S. A., Ahmad, R. B., Malek, M., Yahya, A., Kamaruddin, R. andf Salim, M. (2012) "Smart prolong fuzzy wireless sensor-actor network for agricultural application", Journal of Information Science and Engineering, Vol. 28, No. 2, pp. 295-316. ISSN 1016-2364 
[36] Satyanarayanan, M. (2001) "Pervasive computing: Vision and challenges", IEEE Personal Communications, Vol. 8, No. 4, pp. 10-17. ISSN 1070-9916. DOI 10.1109/98.943998.

[37] Schuster, E. W., Lee, H.-G., Ehsani, R., Allen, S. J. and Rogers, J. S. (2011) "Machine-tomachine communication for agricultural systems: An XML-based auxiliary language to enhance semantic interoperability", Computers and electronics in agriculture, Vol. 78, No. 2, pp. 150-161. ISSN 0168-1699. DOI 10.1016/j.compag.2011.07.002.

[38] Shao, J., Meng, W. and Sun, G. (2017) "Evaluation of missing value imputation methods for wireless soil datasets", Personal and Ubiquitous Computing, Vol. 21, No. 1, pp. 113-123. ISSN 1617-4909. DOI 10.1007/s00779-016-0978-9.

[39] Shi, H.-L., Li, D., Qiu, J.-F., Hou, C.-D. and Cui, L. (2014) "A task execution framework for cloud-assisted sensor networks", Journal of Computer Science and Technology, Vol. 29, No. 2, pp. 216-226. ISSN 1000-9000. DOI 10.1007/s11390-014-1424-y.

[40] Simbeye, D. S. (2020) "Deployment of Wireless Sensor Networks for Soil Macronutrients Measurements in Farms", Proceedings of the International Journal of ICT Research in Africa and the Middle East, pp. 332-346. IGI Global. ISSN 2472-3126. DOI 10.4018/IJICTRAME.2016070103.

[41] Sivamani, S., Bae, N. and Cho, Y. (2013) "A smart service model based on ubiquitous sensor networks using vertical farm ontology", International Journal of Distributed Sensor Networks, Vol. 9, No. 12. ISSN 1550-1477. DOI 10.1155/2013/161495.

[42] Sivamani, S., Choi, J., Bae, K., Ko, H. and Cho, Y. (2018) "A smart service model in greenhouse environment using event-based security based on wireless sensor network", Concurrency and Computation: Practice and Experience, Vol. 30, No. 2. ISSN 1550-1477. DOI 10.1002/cpe.4240.

[43] Steinberger, G., Rothmund, M. and Auernhammer, H. (2009) "Mobile farm equipment as a data source in an agricultural service architecture", Computers and Electronics in Agriculture, Vol. 65, No. 2, pp. 238-246. ISSN 0168-1699. DOI 10.1016/j.compag.2008.10.005.

[44] Stojanovic, V., Falconer, R.E., Isaacs, J., Blackwood, D., Gilmour, D., Kiezebrink, D. and Wilson, J. (2017) "Streaming and 3D mapping of AGRI-data on mobile devices", Computers and Electronics in Agriculture, Vol. 138, pp. 188-199. ISSN 0168-1699. DOI 10.1016/j.compag.2017.03.019.

[45] Tzounis, A., Katsoulas, N., Bartzanas, T. and Kittas, C. (2017) "Internet of Things in agriculture, recent advances and future challenges", Biosystems Engineering, Vol. 164, pp. 31-48. ISSN 1537-5110. DOI 10.1016/j.biosystemseng.2017.09.007.

[46] Van Eck, N. and Waltman, L. (2009) "Software survey: VOSviewer, a computer program for bibliometric mapping", Scientometrics, Vol. 84, No. 2, pp. 523-538. ISSN 1588-2861. DOI 10.1007/s11192-009-0146-3.

[47] Vianna, H. D. and Barbosa, J. L. V. (2017) "In search of computer-aided social support in non-communicable diseases care", Telematics and Informatics, Vol. 34, No. 8, pp. 1419-1432. ISSN 0736-5853. DOI 10.1016/J.TELE.2017.06.005.

[48] Weiser, M. (1999) "The computer for the $21^{\text {st }}$ century", ACM SIGMOBILE mobile computing and communications review, Vol. 3, No. 3, pp. 3-11. ISSN 1559-1662. DOI 10.1145/329124.329126. 